\title{
Benign Partial Epilepsy of Childhood with Monomorphic Sharp Waves in Centrotemporal and Other Locations
}

\author{
Ivo Drury and Ahmad Beydoun \\ EEG Laboratory, Department of Neurology, University of Michigan, Ann Arbor, Michigan, U.S.A.
}

Summary: We reviewed EEGs from children whose history and clinical course was compatible with benign partial epilepsy of childhood with centrotemporal spikes. In $21 \%$ of patients with a single EEG focus, the discharge was outside the centrotemporal area. In $37.5 \%$ of patients with more than one focus, one was in the centrotemporal area while the other was not. We suggest that the typical EEG features of this syndrome are the normal background, the stereotypic morphology of the sharp waves, and their activation by drowsiness and sleep, not their exclusive location in the centrotemporal regions. Insistence on a centrotemporal location for the EEG discharges in this syndrome may lead to a misclassification of the type of epilepsy in some children with implications for therapeutic decisions and prognostic statements. Key Words: Benign partial epilepsy-Child-Electroencephalography.
Benign epilepsy of childhood with centrotemporal spikes (BECCT) is an electroclinical syndrome of childhood included in the revised classification of the epilepsies and epileptic syndromes proposed by the Commission on Classification and Terminology of the International League against Epilepsy (1989). While the Commission recognized that this age- and localization-related epilepsy has a less discrete locus of origin than in patients with symptomatic forms of partial epilepsy such as amygdalohippocampal seizures, it still specifies that it is the centrotemporal regions that are involved in one or both sides. The occurrence of typical clinical manifestations in some children with atypical foci of epileptiform activity as well as the occurrence of typical and atypical foci in the same electroencephalogram (EEG) in some children led us to review the importance of topography of the sharp waves in cases referred to this institution.

\section{METHODS AND MATERIALS}

Each EEG performed between April 1986 and April 1989 in children aged 2-18 years with focal epileptiform activity at the University of Michigan

Received September 1990; revision accepted October 1990.

Address correspondence and reprint requests to Dr. I. Drury at EEG Laboratory, IB300 University Hospital, 1500 E. Medical Center Drive, Ann Arbor, MI 48109-0036, U.S.A.
EEG Laboratory was reviewed. Records that met the following criteria were identified: (a) normal background features: mild background slowing was accepted if attributable to a medication effect; (b) focal, monomorphic spikes or sharp waves that were di- or triphasic with a blunted peak that increased in frequency during drowsiness or sleep if those states were achieved; (c) absence of focal slowing; and (d) absence of other types of significant focal epileptiform activity.

No record was excluded on the basis of topography or multifocality of the discharges.

The medical records of 41 children who met the EEG criteria were then reviewed. Nineteen children also met the following clinical criteria: (a) presence of nocturnal partial or generalized tonic-clonic seizures or partial or secondarily generalized daytime tonic-clonic seizures; (b) normal neurological examination; (c) normal development and intelligence; and (d) no other seizure types.

Twenty-four EEG recordings were performed on these 19 children. Each record was inspected to identify (a) number of foci, (b) topography of the discharges, and (c) the presence of a horizontal dipole (HD).

The discharges were labeled according to the two areas of greatest amplitude on a referential montage to the ipsilateral ear, the first location indicating the most involved area. Recordings were made on 21channel instruments, with electrodes placed ac- 
cording to the International 10-20 system, and utilizing referential, longitudinal bipolar and transverse bipolar montages. Hyperventilation and photic stimulation were performed on all patients. The 24 records included 20 periods of wakefulness, 14 periods of drowsiness, and 6 periods of sleep.

\section{RESULTS}

There were 11 boys (58\%) and 8 girls (42\%). The average age was 7.5 years, with 1 child aged from 2 to 5 years, 16 children from 5 to 10 years, and 2 children between ages 10 and 12 years. The sharp waves were restricted to the right hemisphere in $33 \%$, the left hemisphere in $25 \%$, and were bilateral in $42 \%$. EEG features found in children with one, two, and three foci are discussed individually.

Fourteen EEG recordings showed a single sharpwave focus. In 11 of the records (79\%), the maximal amplitude of the discharge was in the centrotemporal region, 5 of these having a HD. In three (21\%), the discharges were maximal over the parietal or posterior temporal areas, one having a HD (Table 1). Head computed tomography (CT) was normal in the nine examined cases.

Eight records from six patients revealed two independent foci, one from each hemisphere (Table 2). There were four boys and two girls, with an average age of 7.5 years; seven records had a HD in one focus and the other had no HD in either focus. In seven records from five cases, both discharges were of maximum amplitude in the centrotemporal region. In the other case, one focus had its highest amplitude at a location outside the centrotemporal area. Head CT was normal in the two examined cases.

Two records from two girls revealed three independent foci (Table 3). In one record, the foci were in the central, occipital, and posterior-temporal regions (Fig. 1). In the other, the foci had a maximum amplitude in the centrotemporal, occipital, and midline central-parietal regions (Fig. 2A). One patient had a head CT, which was normal.

The location of the sharp waves in patients who

TABLE 1. Topography of the electroencephalographic discharges in patients with a single focus

\begin{tabular}{|c|c|c|}
\hline & $\begin{array}{l}\text { Central or } \\
\text { midtemporal }\end{array}$ & $\begin{array}{c}\text { Other } \\
\text { locations }\end{array}$ \\
\hline $\begin{array}{l}\text { No. of pts. } \\
\text { Average age }\end{array}$ & $11(79 \%)$ & $3(21 \%)$ \\
\hline (years) & 6.5 & 10.5 \\
\hline $\operatorname{Sex}(M / F)$ & $6 / 5$ & $1 / 2$ \\
\hline Horizontal dipole & $5(45 \%)$ & $1(33 \%)$ \\
\hline
\end{tabular}

TABLE 2. Topography of the electroencephalographic discharges in patients with two independent foci

\begin{tabular}{lcll}
\hline Sex & $\begin{array}{c}\text { Age } \\
\text { (years) }\end{array}$ & $\begin{array}{c}\text { Right } \\
\text { hemisphere } \\
\text { focus }\end{array}$ & $\begin{array}{c}\text { Left } \\
\text { hemisphere } \\
\text { focus }\end{array}$ \\
\hline F & 5 & C-P & P-PT \\
M & 7 & C-P & $\begin{array}{l}\text { C-MT } \\
\text { M }\end{array}$ \\
F & 5 & C & $\begin{array}{l}\text { C-MT }^{a} \\
\text { M }\end{array}$ \\
EEG 1 & 7 & C & C-P \\
EEG 2 & 8 & MT-P & MT-C \\
M EEG 1 & 10 & C-MT $^{a}$ & C-P \\
EEG 1 & 12 & MT-P & MT-C \\
EEG 2 & & C-MT & C-P \\
\hline
\end{tabular}

C, central; P, parietal; MT, midtemporal; PT, posterior temporal.

${ }^{a}$ Horizontal dipole present.

had follow-up EEGs is summarized in Table 4. Three patients had two EEGs and one had three EEGs performed. Three patients with more than one focus on the initial record had only one focus on follow-up EEG (Fig. 2A,B). In all four patients, there was a shift in the topography of the discharges between the initial and follow-up EEGs. This occurred from a posterior to a centrotemporal location as well as the reverse.

Five patients had epileptiform discharges outside the centrotemporal area on their initial or follow-up records. Their age of seizure onset was 4-9.5 years (mean of 6 years). This was similar to the 14 children with typical EEG features whose age of seizure onset was 2.5-12 years, with a mean of 6 years. Of these five patients, three had focal motor seizures with orofacial involvement or speech arrest. Two had a few nocturnal generalized tonic-clonic seizures. These five children have been followed for 2-9 years (mean of 5.2 years). They have all been seizure free for 1.5-5 years (mean of 3.2 years).

Of the 22 patients who met the EEG criteria only, 5 had behavioral episodes or headaches, 3 had a single febrile seizure, while 14 had varied types of seizures, e.g., posttraumatic or postencephalitic, associated with developmental delay or developmental anomalies and one case of absence seizures.

TABLE 3. Topography of the electroencephalographic discharges in patients with three independent foci

\begin{tabular}{cclll}
\hline Sex & $\begin{array}{c}\text { Age } \\
\text { (years) }\end{array}$ & $\begin{array}{l}\text { First } \\
\text { focus }\end{array}$ & $\begin{array}{l}\text { Second } \\
\text { focus }\end{array}$ & $\begin{array}{c}\text { Third } \\
\text { focus }\end{array}$ \\
\hline $\mathrm{F}$ & 8 & $\mathrm{O}$ & $\mathrm{O}-\mathrm{PT}$ & $\mathrm{C}^{-\mathrm{MT}^{a}}$ \\
$\mathrm{~F}$ & 10 & $\mathrm{Cz}-\mathrm{Pz}$ & $\mathrm{O}$ & $\mathrm{C}-\mathrm{MT}$ \\
\hline
\end{tabular}

C, central; P, parietal; O, occipital; MT, midtemporal; PT, posterior temporal; $\mathrm{z}$, midline.

${ }^{a}$ Horizontal dipole present. 


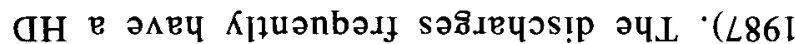

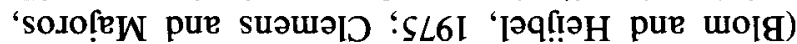

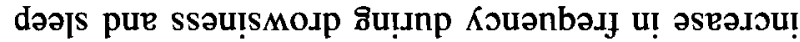
İY) (L86I “'] -

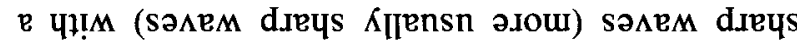

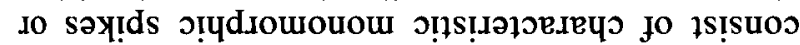

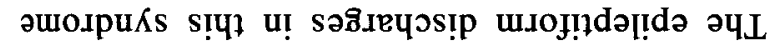

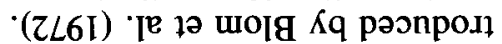
-U! seM 'LつOGg ‘

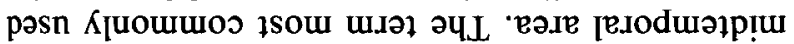

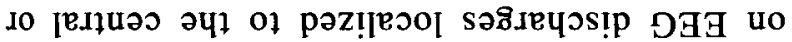

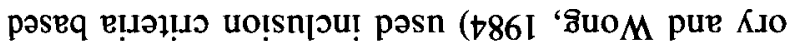

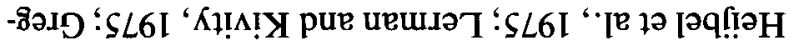

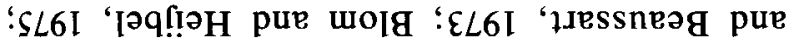

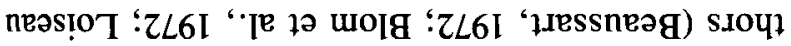

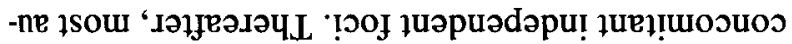

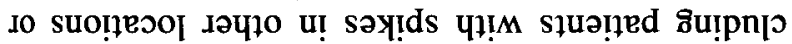

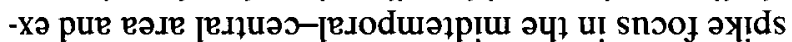

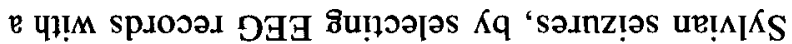

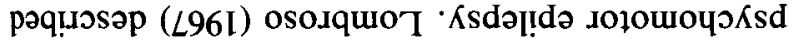

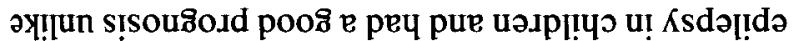

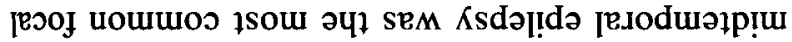

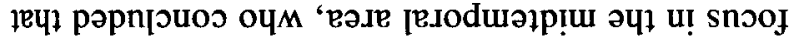

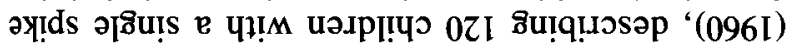

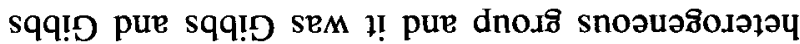

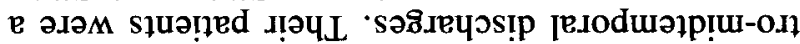

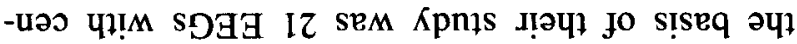

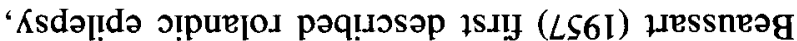

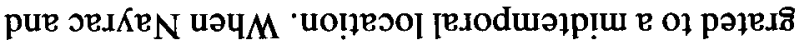

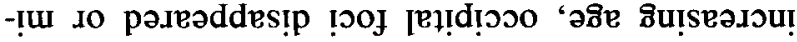

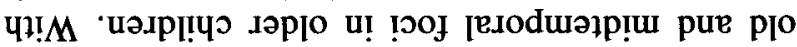

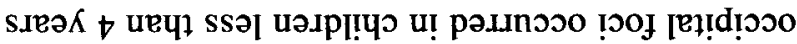

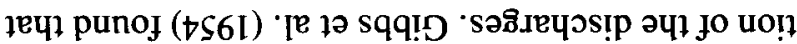

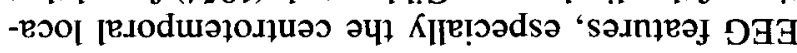

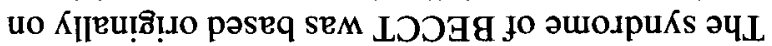

\section{NOISSกOSIA}

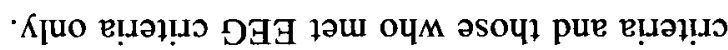

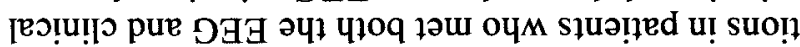

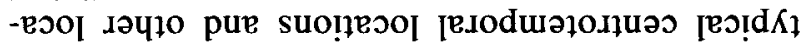

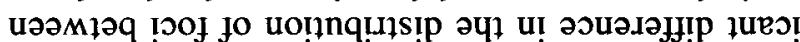

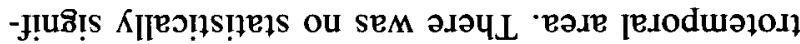

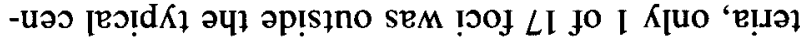

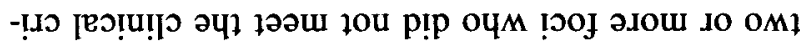

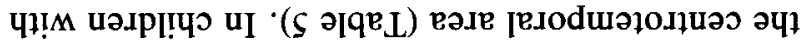

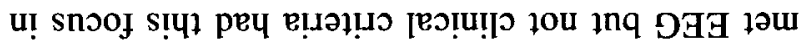

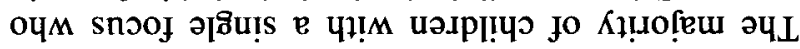

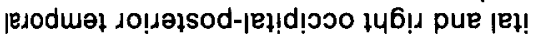

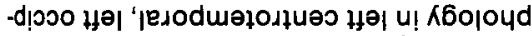

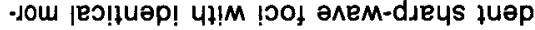

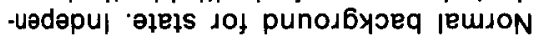

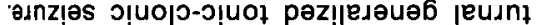

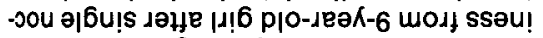

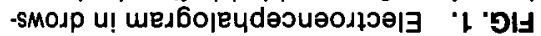

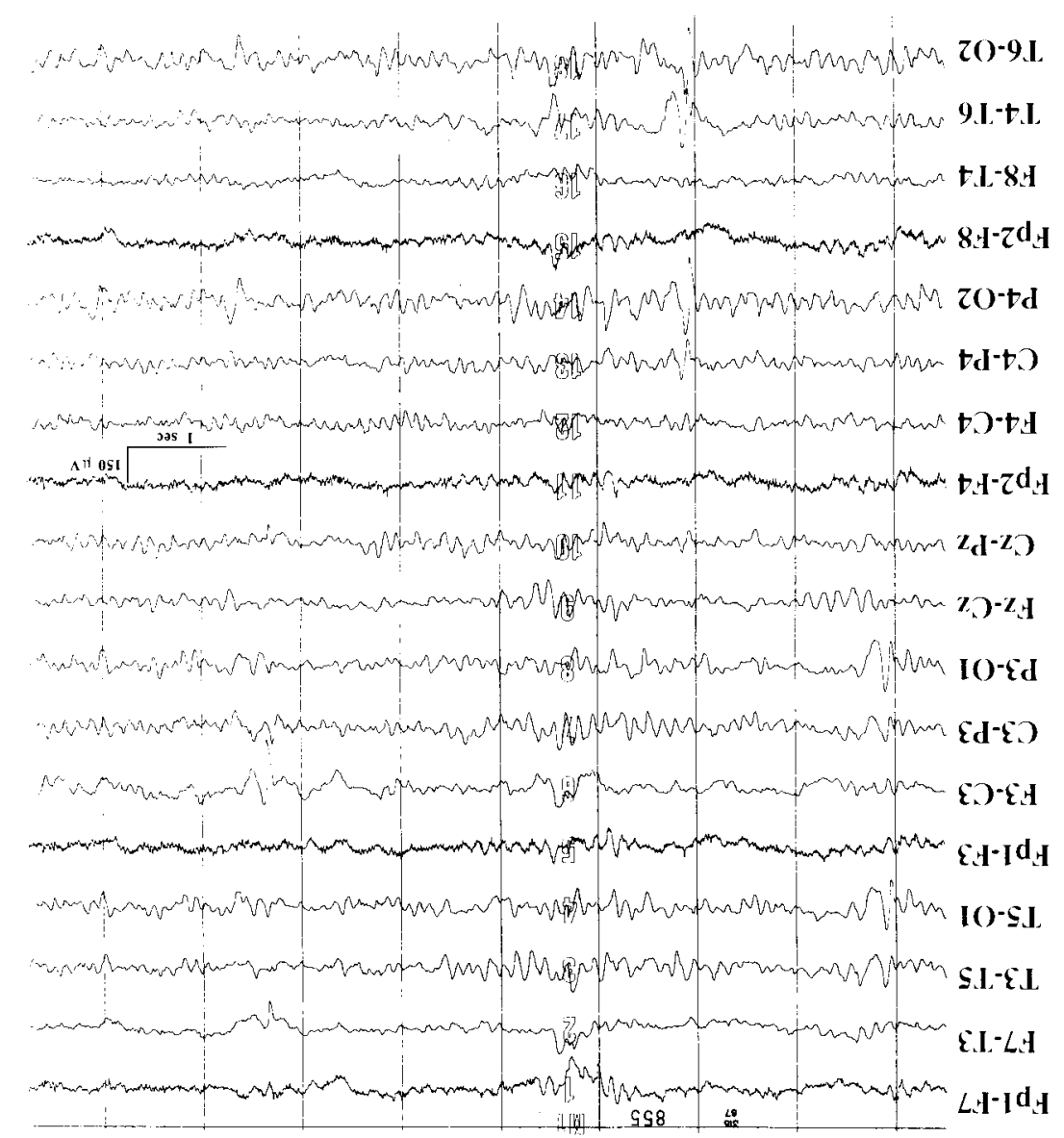


A. Al-T3

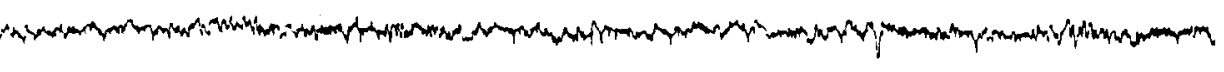

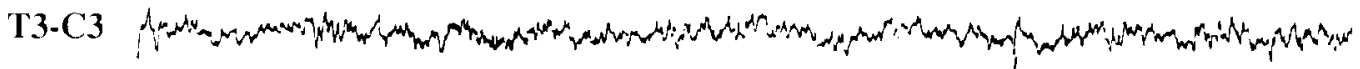

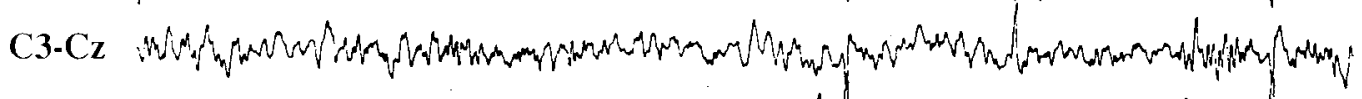

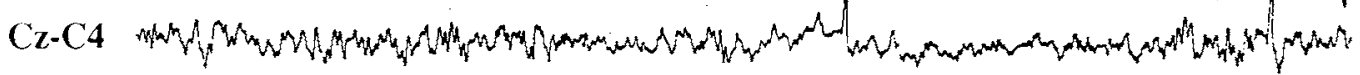

C4-T4

T4-A2

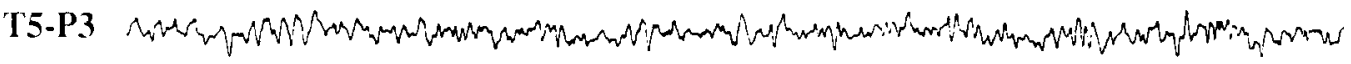

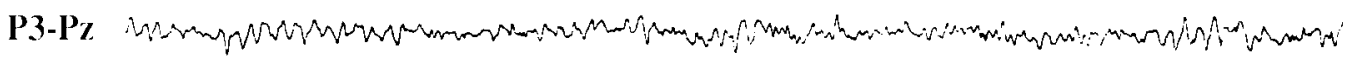

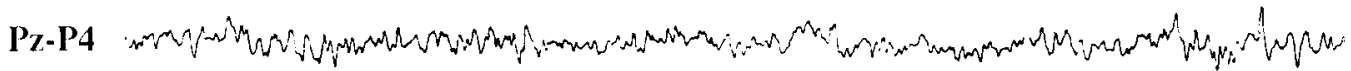

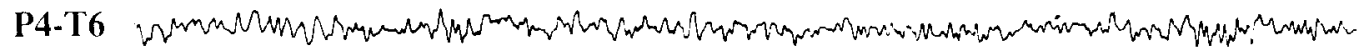

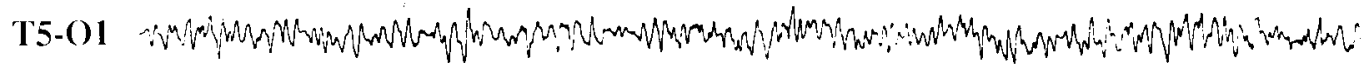

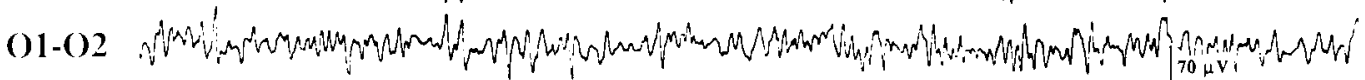

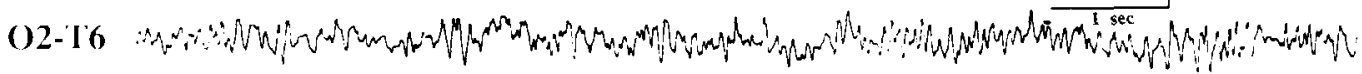

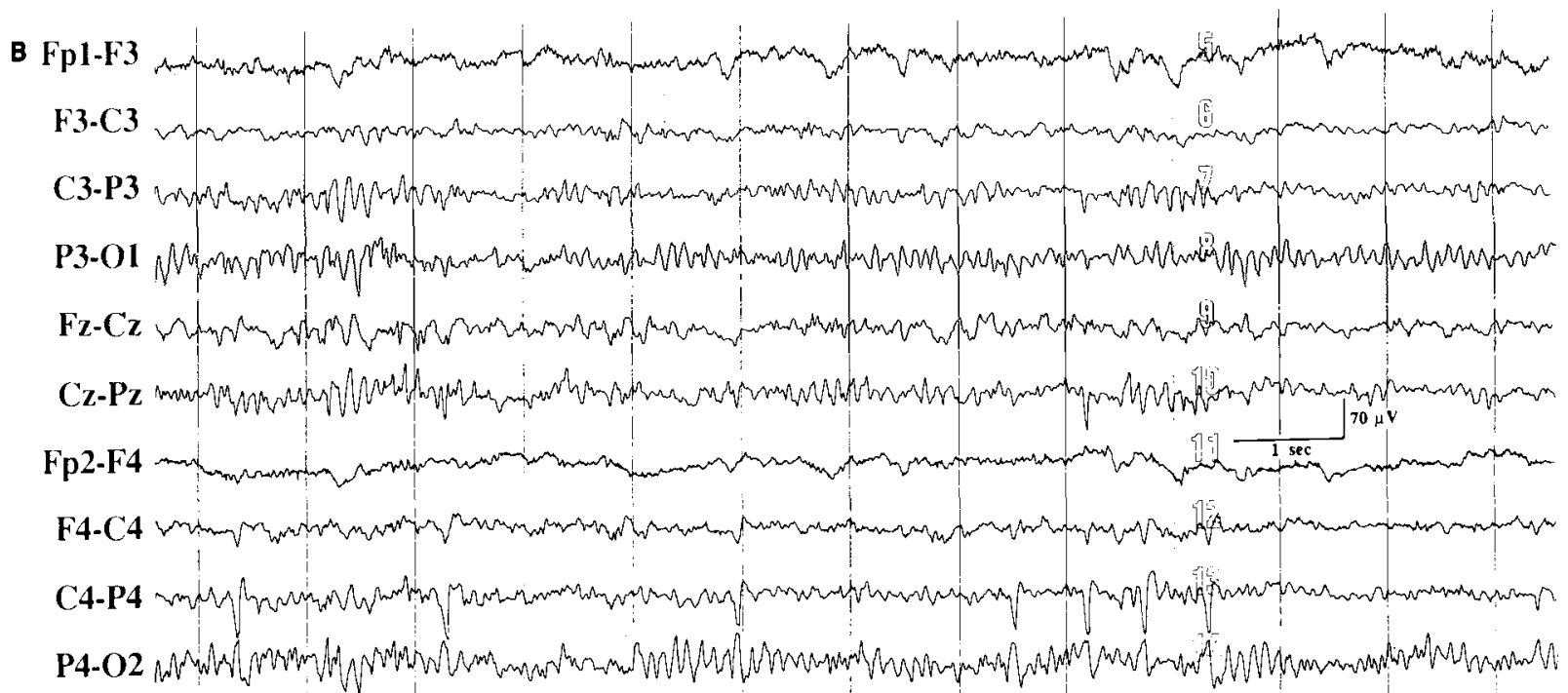

FIG. 2. (A): Electroencephalogram in wakefulness from 10-year-old girl with rare partial seizures consisting of jerking movements of the face and upper extremity. Normal background. Well-developed sharp waves at left centrotemporal and midline central-parietal regions are seen. The independent left occipital sharp waves that occurred in this child are not shown in this particular sample. (B): Electroencephalogram in wakefulness from same patient as in Fig. 2A after a 2-year interval. Normal background; blunted sharp waves occur in clusters in the right parietal region.

(Blume, 1982; Gregory and Wong, 1984; Lüders et al., 1987), and can be unilateral or bilateral and independent. Each of our children had the typical appearance of the sharp waves and activation by drowsiness and sleep irrespective of location.

Twenty-one percent of our patients with a single focus had discharges outside the centrotemporal area, but the history and clinical course of these patients was completely compatible with BECCT.
Others have mentioned that such deviations should be accepted if the rest of the picture is typical (Lerman and Kivity-Ephraim, 1981; Aicardi, 1986; Lüders et al., 1987). Petersen et al. (1983) described findings similar to ours, but based on their EEG criteria they may have included patients with other types of partial seizures. Among our patients with more than one focus, $37.5 \%$ had one location in the centrotemporal area while another was not. This 
TABLE 4. Shift in the topography of the electroencephalographic (EEG) discharges on follow-up EEGs

\begin{tabular}{|c|c|c|c|c|c|}
\hline $\begin{array}{c}\text { Age at } \\
\text { first EEG } \\
\text { (years) }\end{array}$ & $\begin{array}{l}\text { Location of } \\
\text { sharp wave }\end{array}$ & $\begin{array}{c}\text { Age at } \\
\text { second EEG } \\
\text { (years) }\end{array}$ & $\begin{array}{l}\text { Location of } \\
\text { sharp wave }\end{array}$ & $\begin{array}{l}\text { Age at } \\
\text { third EEG } \\
\text { (years) }\end{array}$ & $\begin{array}{l}\text { Location of } \\
\text { sharp wave }\end{array}$ \\
\hline 5 & $\begin{array}{l}\text { L P-PT } \\
\text { R C-P }\end{array}$ & 7 & L C-P & & \\
\hline 10 & $\begin{array}{l}\mathrm{L} \mathrm{C}-\mathrm{MT} \\
\mathrm{L} \mathrm{O} \\
\mathrm{Cz}-\mathrm{Pz}\end{array}$ & 12 & R P & & \\
\hline 10 & $\begin{array}{l}\text { R MT-P } \\
\text { L MT-C }\end{array}$ & 12 & $\begin{array}{l}\text { R C-MT } \\
\text { L C-P }\end{array}$ & & \\
\hline 7 & $\begin{array}{l}\text { L MT-C } \\
\text { R MT-P }\end{array}$ & 8 & $\begin{array}{l}\text { L C-P } \\
\text { R C-MT }\end{array}$ & 10 & L P-C \\
\hline
\end{tabular}

C, central; P, parietal; O, occipital; $\mathrm{z}$, midline; MT, midtemporal; PT, posterior temporal.

$\mathbf{R}$ or $\mathbf{L}$, right or left, respectively.

was described in $10 \%$ of Beaussart's (1972) cases and by others (Lerman and Kivity, 1975; Lüders et al., 1987).

A shift in the location of the discharges was observed by some investigators (Gibbs et al., 1954; Lerman and Kivity, 1975; Lüders et al., 1987), who believe that the discharges "migrate" from a posterior to a centrotemporal location with increasing age. Although our sample was small, we found on follow-up records that the location of the discharges could shift from a posterior to a centrotemporal location and vice versa. Discharges with an occipital location could be easily differentiated from those seen in benign focal epilepsy of childhood with occipital spikes. In that syndrome (Gastaut, 1982), the discharges are spikes rather than blunted sharp waves, they occur in trains with eye closure, are attenuated by eye opening, and are not activated by sleep.

We found that patients with morphologically identical discharges in the centrotemporal and other locations may have a similar history and clinical course, discharges in the centrotemporal areas frequently occur simultaneously with morphologically similar discharges at other locations, and the topography of the discharges can shift from a centrotemporal location to another location and vice versa on follow-up EEGs.

TABLE 5. Sharp-wave topography in 29 electroencephalograms with single focus from patients with and without electroclinical syndrome

\begin{tabular}{lcc}
\hline & $\begin{array}{c}\text { Central or } \\
\text { midtemporal }\end{array}$ & $\begin{array}{c}\text { Other } \\
\text { locations }\end{array}$ \\
\hline $\begin{array}{l}\text { Electroclinical syndrome } \\
\text { Seizures, not electroclinical } \\
\text { syndrome }\end{array}$ & $11(79 \%)$ & $3(21 \%)$ \\
$\begin{array}{c}\text { Behavioral disorder, simple } \\
\text { febrile seizures }\end{array}$ & $7(87 \%)$ & $1(13 \%)$ \\
\hline
\end{tabular}

We believe that the normal background features, the typical morphology, and activation of the discharges in drowsiness and sleep should be the essential EEG criteria of this electroclinical syndrome and not their topography. In view of the exceptionally good prognosis of children with this epileptic syndrome, it is important not to exclude cases who demonstrate all of the typical features accepted to date except for an unusual location of their sharp waves.

Acknowledgment: The authors thank Dr. Fritz E. Dreifuss for review of the manuscript and helpful comments.

\section{REFERENCES}

Aicardi J. Epilepsies characterized by simple partial seizures. In: Aicardi, J, ed. Epilepsy in children. New York, Raven Press, 1986:112-39 (International review of child neurology series).

Beaussart M. Benign epilepsy of children with rolandic (centrotemporal) paroxysmal foci. A clinical entity. Study of 221 cases. Epilepsia 1972;13:795-811.

Blom S, Heijbel J. Benign epilepsy of children with centrotemporal EEG foci. Discharge rate during sleep. Epilepsia $1975 ; 16: 133-40$.

Blom S, Heijbel J, Bergfors PG. Benign epilepsy of children with centrotemporal EEG foci. Prevalence and follow up study of 40 patients. Epilepsia 1972;13:609-19.

Blume WT. Atlas of pediatric electroencephalography. New York: Raven Press, 1982.

Clemens B, Majoros E. Sleep studies in benign epilepsy of childhood with rolandic spikes. II. Analysis of discharge frequency and its relation to sleep dynamics. Epilepsia 1987;28: $24-7$.

Commission on Classification and Terminology of the International League against Epilepsy. Proposal for revised classification of epilepsies and epileptic syndromes. Epilepsia 1989; 30:389-99.

Gastaut H. A new type of epilepsy. Benign partial epilepsy of childhood with occipital spike-waves. Clin Electroencephalogr 1982;13:13-22.

Gibbs EL, Gibbs FA. Good prognosis of midtemporal epilepsy. Epilepsia 1960;1:448-53.

Gibbs EL, Gillen HW, Gibbs FA. Disappearance and migration of epileptic foci in childhood. Am J Dis Child 1954;88:596603.

Gregory DL, Wong PK. Topographical analysis of the centrotemporal discharges in benign rolandic epilepsy of childhood. Epilepsia 1984;25:705-11. 
Heijbel J, Blom S, Rasmuson M. Benign epilepsy of childhood with centrotemporal EEG foci: a genetic study. Epilepsia 1975; 16:285-93

Lerman P, Kivity S. Benign focal epilepsy of childhood. A follow up study of 100 recovered patients. Arch Neurol 1975; 32:261-4.

Lerman P, Kivity-Ephraim S. Focal epileptic EEG discharges in children not suffering from clinical epilepsy: etiology, clinical significance, and management. Epilepsia 1981;22:551-8.

Loiseau P, Beaussart M. The seizures of benign childhood epilepsy with rolandic paroxysmal discharges. Epilepsia 1973; 14:381-9.

Lombroso CT. Sylvian seizures and midtemporal spike foci in children. Arch Neurol 1967;17:52-9.

Lüders H, Lesser RP, Dinner DS, et al. Benign focal epilepsy of childhood. In: Lüders H, Lesser RP, eds. Epilepsy. Electroclinical syndromes. Berlin: Springer-Verlag, 1987:303-46.

Nayrac MMP, Beaussart M. Les pointes-ondes prerolandiques: expression EEG tres particulière. Étude électroclinique de 21 cas. Rev Neurol 1957;99:201-6.

Petersen J, Nielsen CJ, Gulmann NC. Atypical EEG abnormalities in children with benign partial (rolandic) epilepsy. Acta Neurol Scand 1983;67(suppl 94):57-62.

\section{RÉSUMÉ}

Les auteurs ont revu les électroencéphalogrammes (EEG) d'enfants dont les antécédents et l'évolution clinique étaient compatibles avec le diagnostic d'épilepsie partielle bénigne de l'enfance avec pointes centro-temporales. Chez $21 \%$ des patients présentant un foyer EEG unique, les pointes survenaient en dehors de la région centrotemporale. Chez $37.5 \%$ des patients pré- sentant plus d'un foyer, un des foyers était centro-temporal alors que l'autre ne l'était pas. Les auteurs suggèrent que les traits EEG typiques de ce syndrome sont l'activité de fond normale, la morphologie stéréotypée des pointes lentes et leur activation par la somnolence et le sommeil, mais non leur localisation exclusive au niveau de la région centrotemporale. Le fait d'insister sur une localisation centro-temporale pour les anomalies EEG dans ce syndrome pourrait conduire à une mauvaise classification du type de l'épilepsie chez certains enfants, avec les implications que l'on imagine pour les décisions thérapeutiques et l'évaluation pronostique.

(P. Genton, Marseille)

\section{RESUMEN}

Hemos revisado EEGs de niños con una historia y evolución clínica compatibles con epilepsia benigna parcial de la infancia y puntas centrotemporales. En el $21 \%$ de los pacientes con un foco único en el EEG, la descarga se produjo fuera del área centrotemporal. En un $37.5 \%$ con más de un foco, sólo uno se registró en el área centrotemporal. Esto sugiere que los hallazgos típicos del EEG en este síndrome son: una actividad de fondo normal, una morfología estereotipada de ondas agudas activadas por la somnolencia y el sueño y no la exclusiva localización en las regiones centrotemporales. La insistencia en una localización centrotemporal de las descargas en el EEG en este síndrome puede conducir a una falsa clasificación de este tipo de epilepsía en algunos niños con implicaciones en la decisión terapéutica y en las manifestaciones pronósticas.

(A. Portera-Sánchez, Madrid) 